\title{
DESCARTE DE REFUGO EM UMA INSTITUIÇÃO DE CONTROLE AMAZÔNICA: O caso da Vila Santo Antônio do Prata, Pará
}

\author{
WASTE DISPOSAL AT AN AMAZONIC CONTROL \\ INSTITUTION: \\ The case of Vila Santo Antônio do Prata, Pará State
}

\author{
Rhuan Carlos dos Santos Lopes ${ }^{1}$ \\ rhuan.c.lopes@gmail.com
}

\section{RESUMO}

Entre o fim do século XIX e a década de 1970, três instituições de controle se sucederam na Vila Santo Antônio do Prata, situada no município de Igarapé-Açu, estado do Pará. Crianças indígenas, detentos e portadores de hanseníase, formaram os grupos sociais que, respectivamente, estiveram submetidos às diferentes ações de isolamento e sujeição desenvolvidas pelo Estado brasileiro. Considerando isto, este artigo caracteriza as práticas de descarte de refugo, verificadas a partir de escavações arqueológicas realizadas neste local. Os resultados indicaram que o trato com os resíduos diferia das pretensões higienistas observadas nos registros históricos, demonstrando características particulares do cotidiano local.

Palabras clave: Arqueologia Histórica; Lepra; Amazônia brasileira.

\footnotetext{
${ }^{1}$ Instituto de Humanidades (IH), Universidade da Integração Internacional da Lusofonia AfroBrasileira (UNILAB).
} 


\begin{abstract}
Between the end of the nineteenth century and the 1970s, three institutions of control were succeeded in Vila Santo Antônio do Prata, located in the city of Igarapé-Açu, in Pará state. Indigenous children, prisoners and leprosy patients formed the social groups that, respectively, were submitted to the different actions of isolation and subjection developed by the Brazilian State. Considering this, this article characterizes the practices of waste disposal, verified from archaeological excavations performed in this place. The results indicated that the treatment with the residues differed from the hygienic pretensions observed in the historical records, showing particular characteristics of the local daily life.
\end{abstract}

Keywords: Historical Archeology; Leprosy; Brazilian Amazon.

\title{
CONTEXTO DA PESQUISA
}

Instituições de controle têm sido caracterizadas como típicas da formação da sociedade moderna ocidental, particularmente associadas à domesticação dos corpos de diferentes categorias sociais (FOUCAULT, 1977, 1978). Denominados como instituições totais por Goffman (1974), tais lugares possuem certas características comuns, tais como a reunião, por longos períodos, de elevado número de indivíduos de mesma situação social, administrados formalmente na totalidade de suas vidas. Esses estabelecimentos, geridos em contextos europeus, foram sistematicamente utilizados em práticas do tipo colonial em diferentes continentes (FRENCH, 1995; FLEXNER, 2012; BELTRÃO e LOPES, 2014; CASELLA, 2016).

Tendo isto em vista, neste artigo, apresento os resultados das investigações arqueológicas desenvolvidas no âmbito do meu doutoramento, realizadas no sítio 
Vila Santo Antônio do Prata, situado no município de Igarapé-Açu (PA01671), estado do Pará. ${ }^{2}$ Objetivo caracterizar as práticas de descarte de refugo observadas nas escavações realizadas no entorno de algumas das edificações históricas do lugar. Os tipos de depósitos de resíduos são indicativos de diferentes perspectivas de higiene, inclusive contrastantes com o discurso de salubridade relativo, primeiro, a um Núcleo Indígena e, em seguida, ao Leprosário, ambos instalados na Vila em momentos diferentes.

\section{COLÔNIA SANTO ANTÔNIO DO PRATA}

A região da Vila Santo Antônio do Prata (Figura 1), no nordeste do estado do Pará, tem ocupação relacionada às migrações do povo indígena Tembé/Tenetehara, grupo de língua Tupi-Guarani, desde a primeira metade do século XIX. Nesse período, um conjunto de aldeias foi instalado ao longo dos rios Maracanã e seus afluentes, entre eles o rio Prata. Atualmente situada no município de Igarapé-Açu, a Vila foi criada oficialmente em 1898, no conjunto de políticas do governo paraense voltadas à ocupação econômica da região nordeste do Pará. Situada na região cortada pela estrada de ferro Belém-Bragança, seu contexto de criação vincula-se às medidas de expansão econômica, pautadas na criação de núcleos coloniais agrícolas (CRUZ, 1955). O assentamento instalado às margens do Prata, porém, possuía uma especificidade: estava destinado à "civilização" dos Tembé (BELTRÃO e LOPES, 2014).

\footnotetext{
${ }^{2}$ Projeto de pesquisa autorizado pela Portaria Iphan $\mathrm{n}^{\circ}$. 46, de 5/09/2014, publicada no DOU 172 ,
} de 8/09/2014, seção 1, páginas 8 e 9. Processo n. ${ }^{\circ}$ 01492.000316/2014-8. 


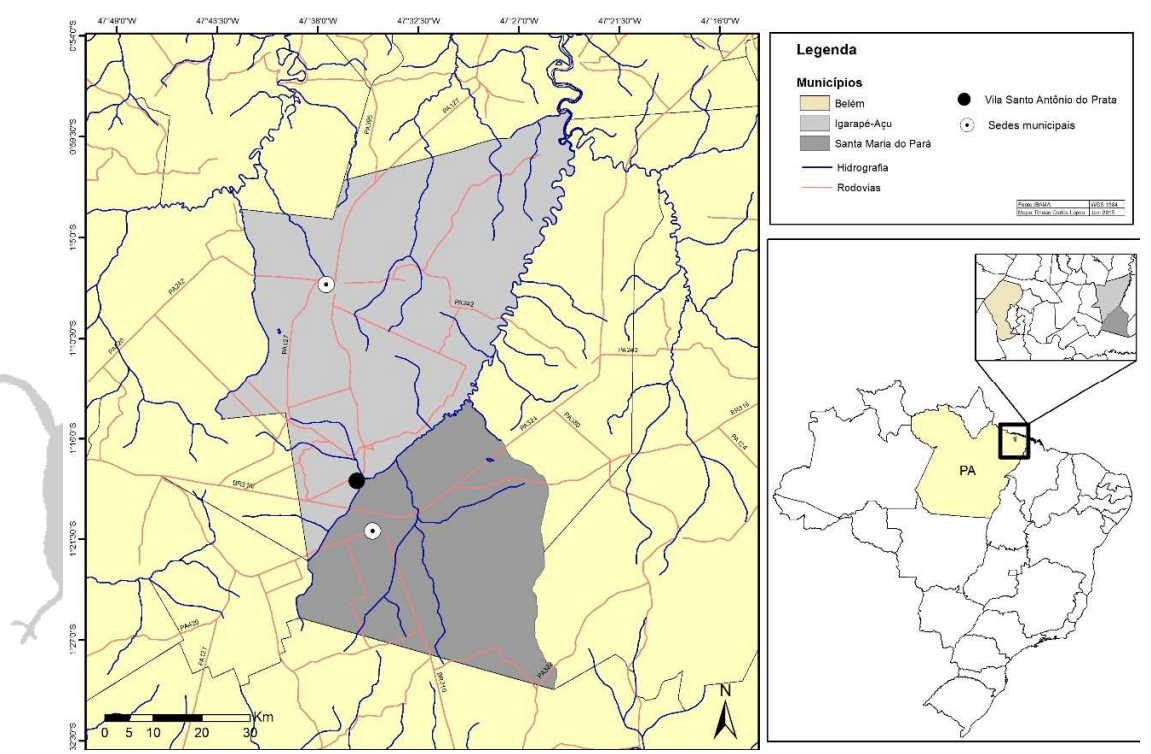

Figura $\quad 1$. Localização da Vila Santo Antônio do Prata, município de Igarapé-Açu, Pará.

Denominado inicialmente de Núcleo Indígena do Maracanã, a colônia foi instalada sobre uma das aldeias dos Tembé. O governo paraense, então, distribuiu colonos não-indígenas em lotes de terra, além de incluir dois educandários, administrados pelos padres Capuchinhos e destinados às crianças indígenas e "meninos desviados" oriundos de Belém (MUNIZ, 1913). Apesar da presença de colonos e alunos não indígenas, o foco era a integração dos Tembé à sociedade nacional. Por isso, as escolas em regime de internato tiveram a preponderância maior, na medida em que nelas era viável a execução do controle cotidiano sobre os corpos das crianças ali matriculadas. Dois prédios foram erguidos para esse fim, um para o Instituto Masculino e outro para o Feminino, cada um deles com atividades específicas para o gênero a qual se destinavam (FERNANDES, 2015). 
No início da década de 1920, no entanto, o governo paraense entendeu que não havia mais indígenas para serem atendidos na Colônia e, então, a estrutura física do perímetro urbano foi convertida em Centro de Correção. Para a nova instituição, foram enviados alguns dos prisioneiros da Cadeia de São José, em Belém, iniciando suas atividades em agosto de 1921. Apesar de haver informações insuficientes sobre o funcionamento desta instituição, sabe-se que os prédios dos institutos educacionais foram utilizados como carceragem. Pouco tempo depois, em 1922, a então Colônia de Correção foi transmutada em Lazarópolis do Prata, oficialmente inaugurada em 1924. Com a finalidade de isolar os doentes de hanseníase do estado do Pará, o local foi escolhido em função de sua proximidade com a capital, relativo isolamento, mas com facilidade de acesso pela Estrada de Ferro de Bragança, e pela estrutura pré-existente (SOUZA ARAUJO, 1924).

As atividades da Lazarópolis foram iniciadas nas edificações existentes desde o início do século $\mathrm{XX}$, correspondente ao antigo núcleo urbano da Colônia Indígena, redefinida como perímetro de isolamento. A implantação desse Leprosário implicava na utilização das normas médicas-sanitárias vigentes no início do século XX. O isolamento foi a regra elementar e a retirada dos antigos moradores dos lotes agrícolas do entorno do Prata era essencial para a criação de um cinturão que garantisse margem de segurança contra possíveis contaminações (SOUZA ARAUJO, 1924). 
Como local que conjuga residência e trabalho, definido pelo controle de espaço e cotidiano, as escolas, prisões e leprosário do Prata encarnam a noção de instituição total (GOFFMAN, 1974). Nesses lugares era exercitado o poder ensejado no investimento político no corpo, que imbrica violência e ideologia (FOUCAULT, 1977). Tal investimento é executado na disciplinarização que atua sobre o corpo dos sujeitos, com o principal fito de torná-los submissos e dóceis à ordem estabelecida ideologicamente. A disciplina é incorporada, então, na organização do espaço, gerido com fins de racionalizar o cotidiano e facilitar a vigilância. Isso implica, também, no espraiamento do exercício do poder, proporcionando a sua reprodução e mantendo o mecanismo de controle.

Assim, a ocupação, por diferentes instituições totais, do mesmo espaço construído é aqui interpretada como a continuidade da lógica de controle e exclusão (FOUCAULT, 1977, 1978), primeiramente aplicada aos indígenas, depois a segmentos considerados espúrios à sociedade, como criminosos e portadores de doença contagiosa. Desse modo, a atual Vila Santo Antônio do Prata é espaço privilegiado para a caracterização, a partir da arqueologia, de uma instituição disciplinar. A sua organização espacial tentou, primeiro, condicionar os corpos dos Tembé ao projeto de civilização através da educação e, depois, utilizou-se do mesmo espaço para, por meio da prisão, do hospital e edifícios auxiliares, controlar os reclusos prisionais e internos hansenianos (LOPES, 2017). Três instituições de controle do Estado, portanto, foram alocadas fora da capital, para isolar e controlar aqueles que não se adequavam às normas e deveriam ser 
mantidos afastados da sociedade: indígenas, criminosos e leprosos. Em função disto, defendo o argumento de que essa infraestrutura material foi constituída enquanto tecnologia de poder sobre os corpos dos grupos a ela submetidos, com objetivos de políticas que tinham como pressuposto o binômio exclusão e reclusão.

\section{SÍTIO ARQUEOLÓGICO SANTO ANTÔNIO DO PRATA}

A delimitação do sítio arqueológico foi realizada a partir da identificação das edificações históricas, em arruinamento ou em uso pelos atuais moradores. Foram localizadas 29 estruturas, com distribuição em um raio de aproximadamente $2 \mathrm{~km}$ a partir do centro urbano da Vila, diminuindo a frequência nas áreas marginais (LOPES e SCHAAN, 2016) (Figura 2).
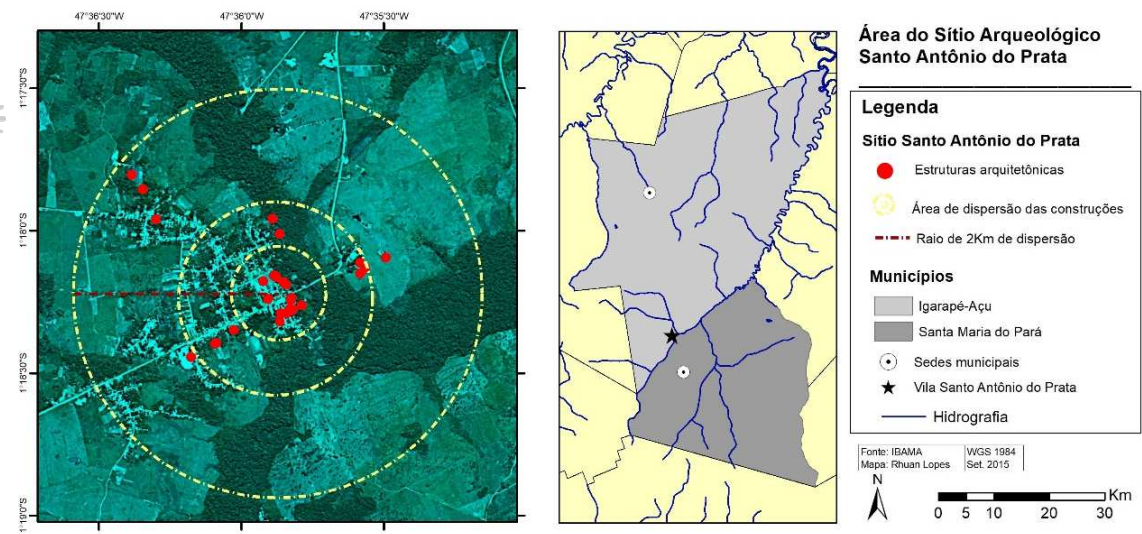

Figura 2. Área do sítio arqueológico Vila Santo Antônio do Prata, município de Igarapé-Açu, Pará.

$\mathrm{Na}$ área central da Vila, a topografia é plana, justamente no local onde está instalada a maioria dos prédios. Na zona mais marginal, a nordeste, na qual havia Indexadores: Latindex, ISIS, Google Academic 
uma estrada de ferro, estação do trem e forno crematório, ocorre desnível maior no terreno, em direção ao rio Prata. Apesar da identificação dessas estruturas, não foi possível, ainda, verificar a funcionalidade de parte delas. Contudo, deduzo que o raio de distribuição das construções verificadas no levantamento arqueológico indique o alcance de controle direto exercido de acordo com as particularidades de cada instituição disciplinar (LOPES, 2017), tendo em vista a sua organização em um modelo panóptico (Foucault, 1977). A concentração de edificações corresponde ao que foi denominado de "núcleo urbano", durante o Núcleo Colonial Indígena (1898-1921); e, depois, "perímetro de isolamento”, no período da Lazarópolis (1924-1980).

\section{PESQUISA ARQUEOLÓGICA}

Com o objetivo de estabelecer relação entre edificações e os depósitos de lixo, tanto do ponto de vista cronológico, quanto dos padrões diferenciados de deposição, as intervenções arqueológicas foram realizadas nas áreas adjacentes de quatro edificações: Forno Crematório, Cozinha Geral, Maloca Frei Carlos e Pavilhão D (Figura 3). Considerei a potencial relação entre os "testemunhos fixos entre si", nesse caso os prédios/lixeiras/buracos de lixo, e os vestígios de menor porte, outrora descartados como lixo (TOCCHETTO, 2010: 22). Apesar das limitações quanto à utilização de tradagens para definir distribuição de material arqueológico em contextos históricos e urbanos (SOUZA, 2014), foi possível localizar estruturas de deposição de refugo com características particulares nas 
áreas do Forno Crematório, da Cozinha Geral e do Pavilhão D. Em função disso, nesses locais ocorreu abertura de unidades de escavação.

Sítio Arqueológico
Santo António do Prata

Áreas das intervenç̧ốes arqueológicas

(2015)
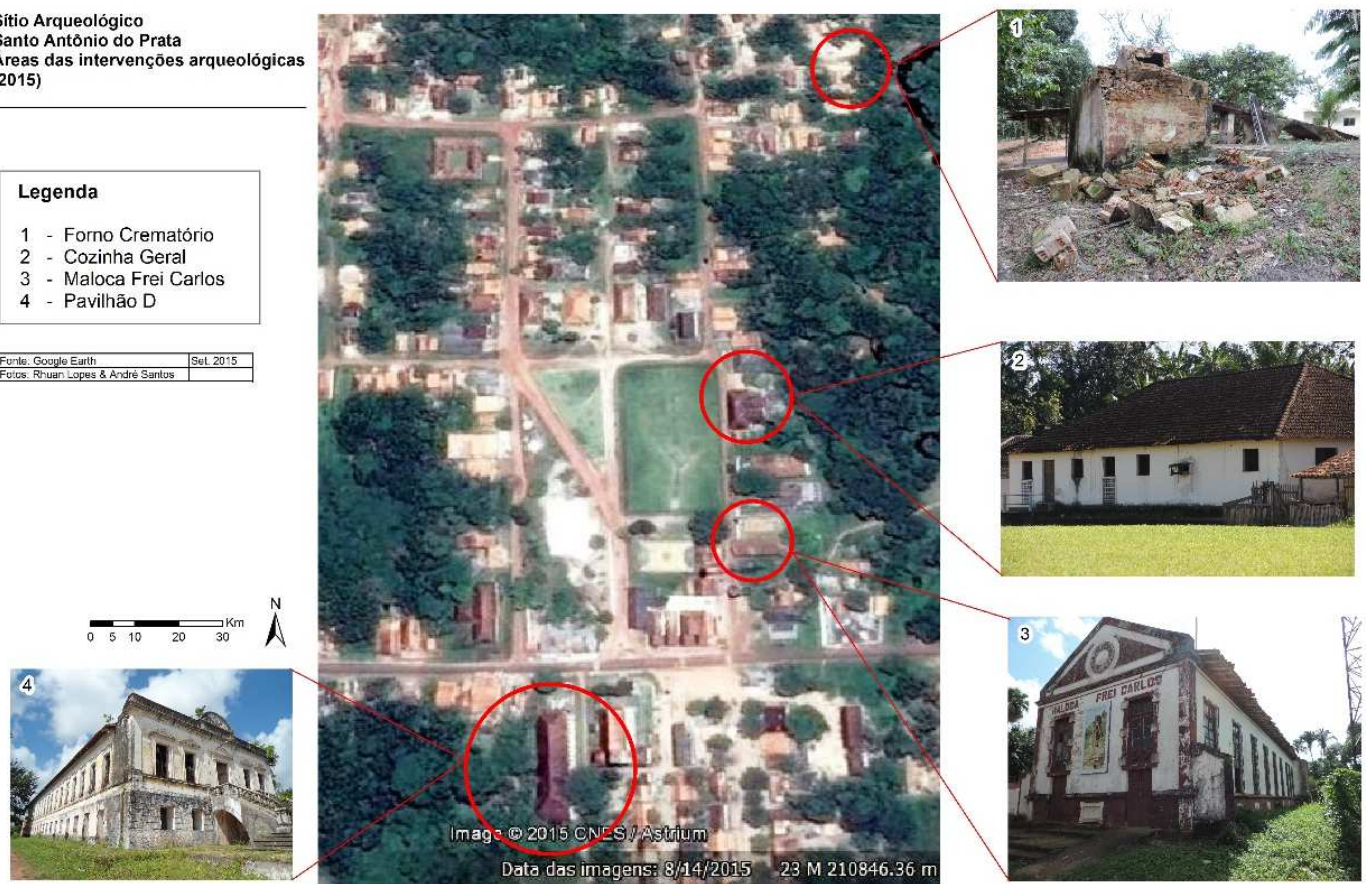

Figura 3. Localização das áreas das intervenções arqueológicas.

\section{Pavilhão D}

Entre as construções que tiveram seu entorno escavado, o Pavilhão D e Maloca Frei Carlos são as mais antigas. Ambos os prédios começaram a ser construídos no início do século XX, no conjunto de obras da Colônia Indígena, para as atividades dos institutos educacionais destinadas às crianças Tembé. Sua 
construção foi iniciada em 1900 e finalizada em 1905 (MUNIZ, 1913). Na sua porção posterior havia, em 1923, alguns prédios anexos: cozinha, carpintaria, alojamento para empregados, curtume - reutilizado como lavanderia pelo Leprosário (SOUZA ARAUJO, 1924). Voltado para o Largo de Santo Antônio, o Pavilhão D fica ao lado da igreja do Prata. Em tempos de Leprosário, o prédio recebeu a denominação "Pavilhão D" e abrigava os homens adultos. Na década de 1990, segundo os moradores, houve reformas no prédio para uso escolar ${ }^{3}$.

Para as intervenções arqueológicas, foi selecionada a porção sul do prédio, que diz respeito à sua face posterior (Figura 4). Conforme os estratos verificados na escavação, observou-se a presença de um horizonte de solo rígido e amarelado, sobre uma camada de restos de materiais construtivos (entulho) associados com uma moeda de 1988. Nos níveis inferiores, coletou-se fragmentos de ossos de animais, um sapato produzido em plástico, além de dois botões e 15 fragmentos vítreos e pequenas garrafas de vidro. Por fim, verificou-se um piso em concreto, no qual não foi realizada escavação.

Provavelmente, o bolsão foi selado com aterro de cor amarelada e a área era utilizada para caminhamento, considerando a rigidez desse horizonte e a grande fragmentação dos vestígios arqueológicos nos níveis iniciais. A moeda de 1988,

${ }^{3}$ Entrevista realizada em julho de 2014. Em função dos estigmas vinculados à hanseníase, os exinternos do leprosário sofrem, ainda, com pré-conceito. Por conta disso, para resguardar as identidades dos interlocutores, seus nomes não são citados. 
coletada nos níveis iniciais, é indício do terminus post quem do entulho. Assim, é provável que o material verificado a partir dos $35 \mathrm{~cm}$ seja proveniente de outras atividades, considerando as mudanças na textura e coloração do solo e o diferente padrão de objetos verificados entre os 75 e $83 \mathrm{~cm}$, acima do piso em concreto, e distribuídos aleatoriamente, apresentando características de refugo primário. Nos níveis superiores, porém, as características são de refugo secundário. A segunda maior frequência de material arqueológico, depois do material construtivo, coletado no Pavilhão D é de vidro, com 696 peças, sendo $84 \%$ da amostra, muito fragmentadas, com características morfológicas indicam produção no século XX.
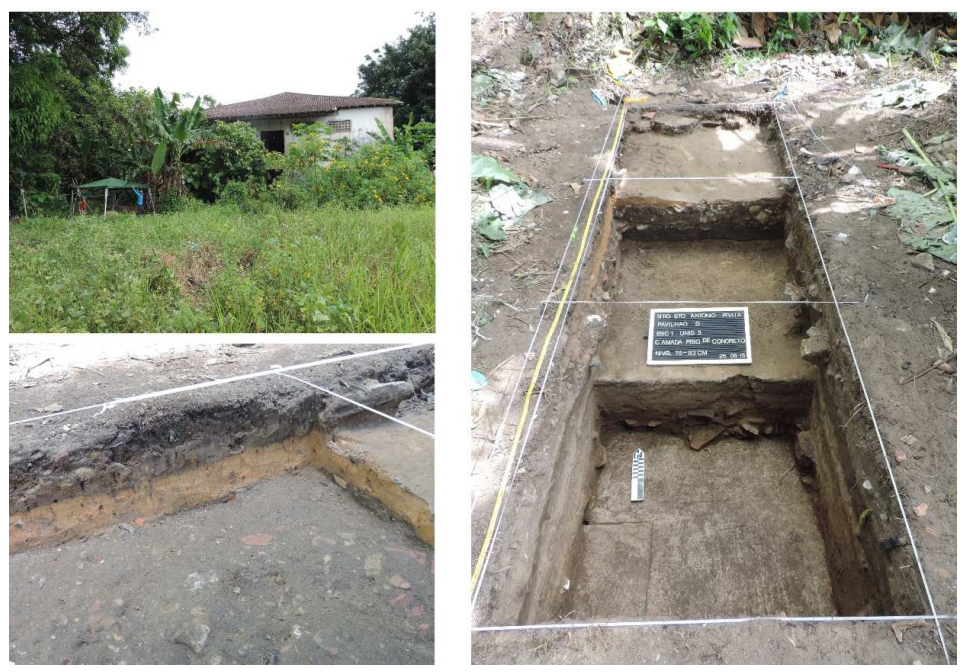

Figura 4. Área da Escavação 1-Pavilhão D. No canto superior esquerdo, panorâmica da porção posterior ao Pavilhão D; no canto inferior esquerdo, horizonte amarelado no perfil da unidade 2Pavilhão $\mathrm{D}$ e fragmentos de entulho construtivo; à direita, finalização da escavação, com os diferentes horizontes e níveis escavados. 


\section{Cozinha Geral}

A Cozinha Geral localiza-se ao lado das ruínas do antigo pavilhão feminino do Leprosário - anteriormente destinado ao Instituto Masculino do Núcleo Colonial Indígena. Há poucas informações históricas sobre o prédio. Em 1930 o jornal Folha do Norte informou sobre a aquisição de "cozinha a vapor", equipamento utilizado para cozimento das refeições. Anos depois, Souza Araujo (1948) confirma que esse equipamento foi instalado em prédio adaptado às necessidades de uma cozinha. Uma das ex-internas do leprosário, ${ }^{4}$ narrou que a Cozinha atual já existia quando chegou ao Prata, em 1954; e anexo a esta edificação, havia o refeitório geral. Paralela ao rio Prata, a Cozinha Geral integra um dos quarteirões destinados também à construção das oficinas e lavanderia. De todo modo, a Cozinha atendia aos internos que viviam coletivamente nos Pavilhões, em tempos do leprosário.

Nas intervenções arqueológicas, pretendeu-se verificar zonas de deposição de lixo, marginais a essa área de produção do Leprosário. Por outro lado, por estar próxima à margem direita do rio Prata, havia potencial para os registros referentes à ocupação indígena, indicadas nos documentos históricos do século XIX - mas esse tipo de vestígio não foi verificado. Na trincheira de escavação, a aproximadamente 10 metros do rio Prata, foi verificada a presença de um buraco

\footnotetext{
${ }^{4}$ Entrevista realizada em julho de 2014.
} 
de lixeira, coberto com entulho construtivo e solo escurecido. Na porção superior, constatou-se a presença de manilhas cerâmicas utilizados para drenagem de águas pluviais ou esgoto. Aparentemente, o entulho construtivo verificado nas escavações e disperso no terreno diz respeito ao arruinamento do pavilhão de internamento próximo à Cozinha. Contudo, no que diz respeito ao lixo, a rigor, refere-se ao descarte efetuado pelos funcionários da Cozinha, que funciona ainda hoje. As características da topografia local, os níveis estratigráficos pouco definidos e o material arqueológico associado a uma estrutura de escoamento de esgoto sanitário indicam que o bolsão sofreu revolvimento, talvez ocasionado pela limpeza do terreno mais próximo à Cozinha e destruição do sistema de drenagem.

O material em profundidade, em sua maioria, estava posicionado verticalmente, indicando despejo proposital. A maior parte dos vestígios arqueológicos é composto por fragmentos vítreos ou garrafas de vidro, somando 772 objetos ou fragmentos. Um fragmento de louça com decoração e outros 33 de louça branca, sete fragmentos de cerâmica, copos e canecas metálicas, além de 133 fragmentos de ossos de animais foram coletados nos níveis mais profundos.

Dentre os vestígios da categoria louça, as análises em laboratório identificaram a presença significativa de pratos, seguido por pires, xícaras, canecas, tigelas e potes. Somam-se a isso as 12 garrafas para bebidas, com características morfológicas do século XX. Em algumas das embalagens plásticas de alimentos havia data de fabricação conservada, indicando produção entre as décadas de 1980 
e 2000, a maior parte delas presente nos dois níveis iniciais. Quanto ao material osteológico coletado, as análises indicaram a ocorrência de ossos animais utilizados em práticas alimentares, tais como bovinos, caprinos e peixes (VALDEVINO e AMARAL, 2017).
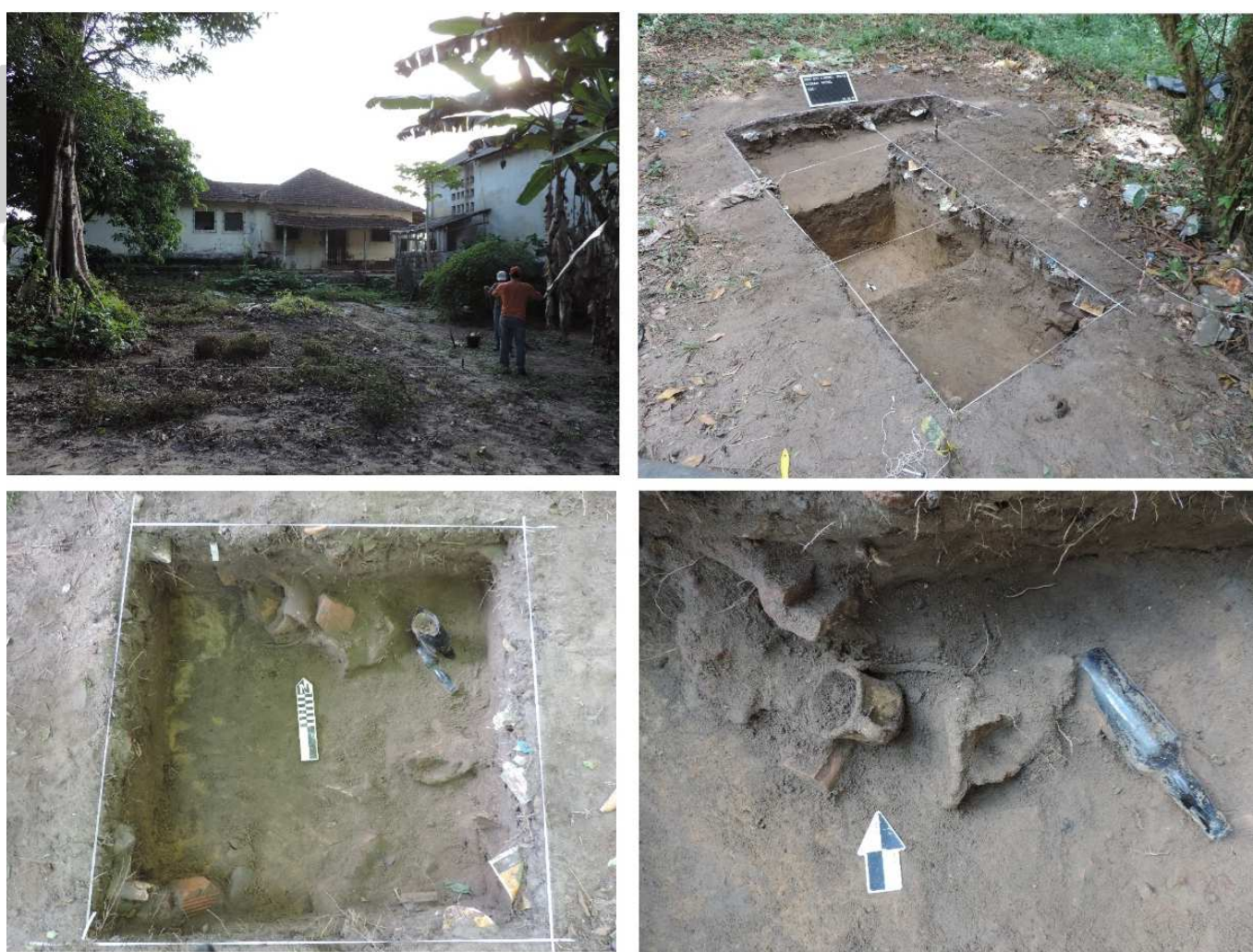

Figura 5. No canto superior esquerdo, área posterior da Cozinha Geral; no canto superior direito, panorama da escavação I-Cozinha Geral; no canto inferior esquerdo, material na base do nível $30-40 \mathrm{~cm}$; e no canto inferior direito, pormenor evidenciando garrafa de vidro, material metálico, caneca e entulho construtivo.

Indexadores: Latindex, ISIS, Google Academic

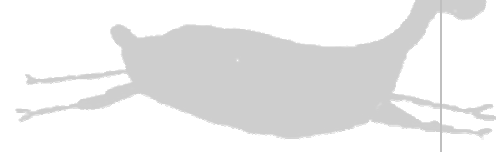




\section{Forno Crematório}

Há escassez de informações disponíveis sobre a construção do Forno Crematório. Na sua área, na década 1910, situava-se "a estação central da Ferro Carril do Prata, à qual está anexo o galpão de depósito da mesma” (MUNIZ, 1913:14). Na década de 1920, durante o funcionamento do leprosário, um "incinerador" estava previsto entre as modificações para atender às necessidades da instituição hospitalar (SOUZA ARAUJO, 1924). Um dos ex-internos do Prata, morador do local desde 1938, afirma que todo o lixo dos pavilhões era coletado em carroças e depositado na fornalha do Forno. ${ }^{5}$ Assim, deduz-se que o mesmo foi construído em tempos da Lazarópolis, após a década de 1940, como medida sanitária recorrente nesse tipo de instituição localizadas no Brasil no mesmo contexto. Sua estrutura assemelha-se ao forno de incineração de lixo da Colônia Santa Teresa, no estado de Santa Catarina, com funcionamento similar ao descrito pelo entrevistado citado acima (SOUZA ARAUJO, 1948) (Figura 6).

Em 2012, quando a pesquisa etnográfica no Prata foi iniciada (LOPES, 2017), o Forno Crematório estava em funcionamento, recebendo o lixo domésticos das casas adjacentes e das unidades de saúde do Prata. Em 2014, parte da construção foi demolida pelos moradores locais. Segundo um deles, ${ }^{6}$ a derrubada ocorreu tanto pela ameaça de desabamento da chaminé, quanto por conta do incômodo

\footnotetext{
${ }^{5}$ Entrevista realizada em maio de 2014.

${ }^{6}$ Entrevista realizada em julho de 2015.
}

Indexadores: Latindex, ISIS, Google Academic 
causado pela fumaça gerada na queima de diferentes resíduos, inclusive hospitalar.
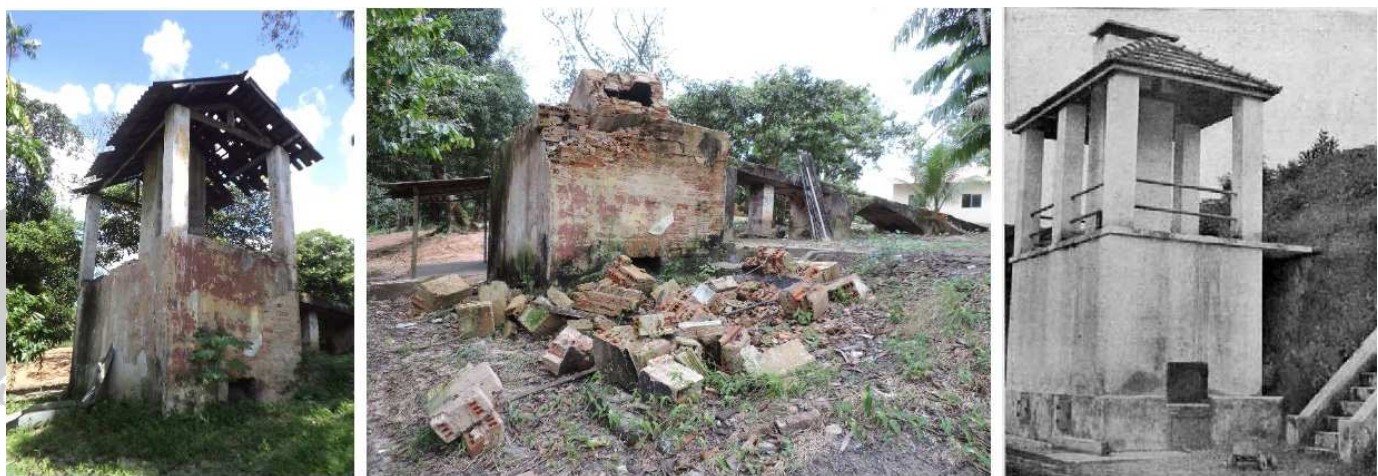

Figura 6. À esquerda, Forno Crematório antes da demolição da chaminé; no centro, panorama da porção norte do Forno Crematório, após a demolição; à direita, incinerador da Colônia Santa Teresa, no estado de Santa Catarina. Fotos: Rhuan Lopes (2012, 2014); Souza Araujo (1948).

Na escavação em trincheira realizada ao lado do Forno Crematório (Figura 7), verificou-se a presença de um piso em cimento e uma estrutura com tijolos posicionados na horizontal, pedras e argamassa, além da ocorrência de fragmentos metálicos, indicando a fundação de uma parede. Uma moeda com data de 1970 foi coletada em meio a esse alicerce. Nos níveis anteriores, a ocorrência foi de entulho construtivo sobre o piso, com pequenas associações ao lixo doméstico contemporâneo proveniente das casas do entorno. Nessa porção também foi coletado um fornilho de cachimbo de argila. 
Considerando a extensão do piso e entulho construtivo verificado em todas as unidades, deduz-se que a porção norte do Forno Crematório foi aterrada com a finalidade de construção de estrutura contígua ao Forno. Essa área plana se estende aproximadamente até $30 \mathrm{~m}$ ao norte da estrutura, com ocorrência de outro piso e uma base de coluna a $25 \mathrm{~m}$, fora da área escavada, mas visíveis em superfície. A presença de entulho construtivo e telhas sobre o piso escavado, além da estrutura de parede, indica uma construção fechada e com cobertura. Todavia, não foi possível indicar a continuidade entre o piso escavado e as estruturas mais ao norte do Forno. Considerando a presença da moeda de 1970 próxima à estrutura demolida da parede, indicando o seu terminus post quem, a estrutura poderia ser uma construção de apoio às atividades do Forno.

Por outro lado, grande quantidade de ampolas e objetos vítreos utilizados nas práticas médicas foi coletada nas tradagens da porção leste do Forno Crematório, com maior frequência nas tradagens próximas ao Forno. Assim, é provável que os fragmentos de vidro correspondentes às práticas médicas verificados sobre o piso localizado na escavação sejam relativos à circulação de pessoas no entorno do Forno Crematório ou a objetos com datação mais recente, considerando que o Forno continuou a ser utilizado até a década de 2010. 

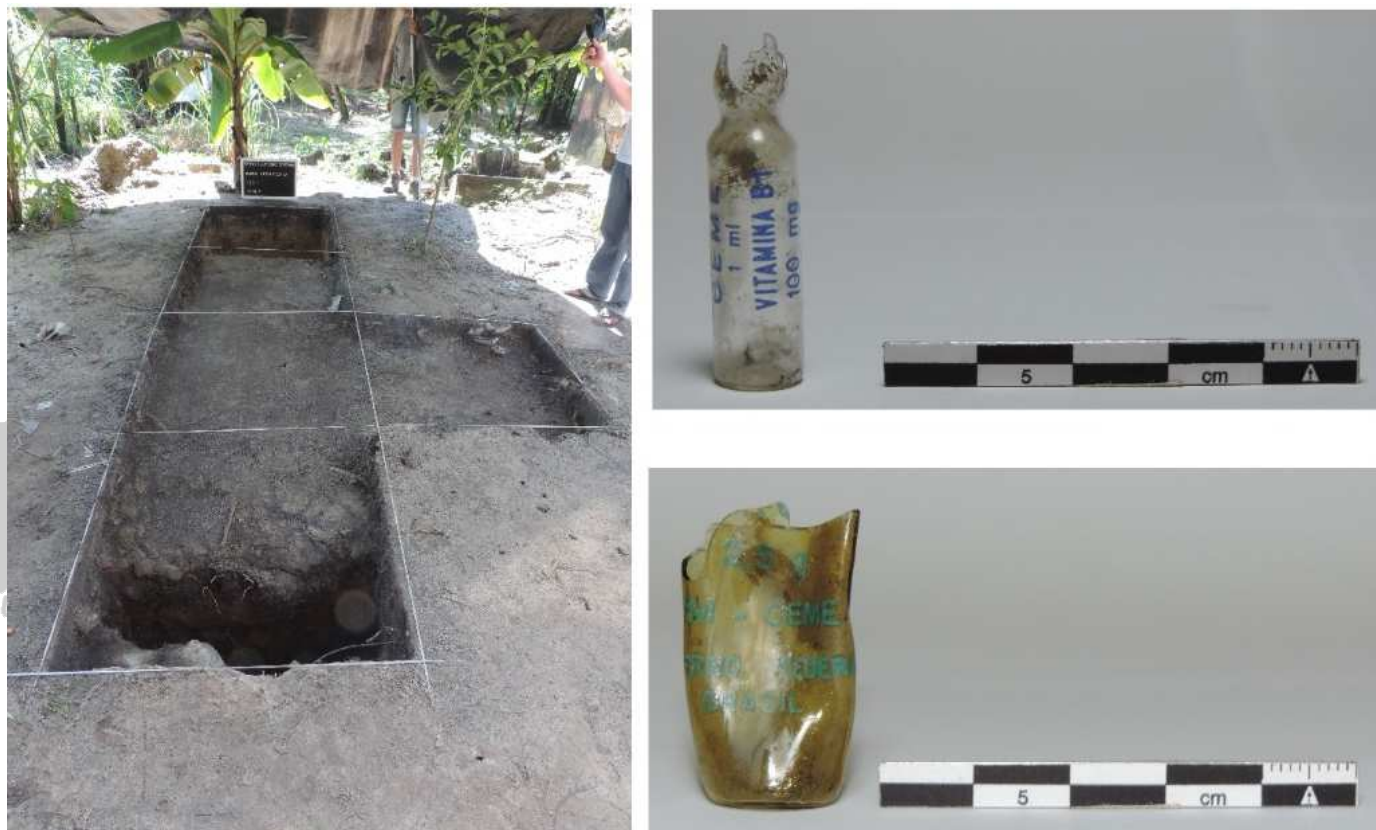

Figura 7. À esquerda, panorama da escavação contígua ao Forno Crematório; à direita, ampolas coletadas nas tradagens. Fotografias do autor.

\section{OS PADRÕES DE DEPOSIÇÃO}

O registro arqueológico é um fenômeno contemporâneo, condicionado por processos culturais e naturais (SCHIFFER, 1985, 1987). As condicionantes culturais dizem respeito a agência humana no uso de artefatos, seja no contexto sistêmico, seja na formação do contexto arqueológico. Quanto aos processos naturais, chamados de tipo não-cultural, referem-se aos fatores ambientais que têm ação sobre os depósitos arqueológicos. O contexto sistêmico diz respeito à utilização dos objetos no sistema comportamental, enquanto o contexto 
arqueológico corresponde aos artefatos em interação com o ambiente natural, depositados após uso no contexto sistêmico (SCHIFFER, 1987).

Para sítios históricos, em particular em conjuntos do tipo urbano, a sucessão de ocupações, movimentação de solo, formação de aterros, demolições, reutilização de edificações, são características que garantem particularidades aos depósitos arqueológicos (SOUZA, 2014). Seguindo a proposição de Symanski e colaboradores (2015) e Suguimatsu e Symanski (2015) para o estudo de práticas de descarte de refugo, os padrões de deposição no sítio Vila Santo Antônio do Prata foram analisados de acordo com a terminologia de Schiffer (1987) e South (1977). Segundo o primeiro autor, o refugo pode ser categorizado como: primário, quando o descarte do material ocorre no local de uso; secundário, quando as áreas de descarte e utilização são diferentes. Soma-se a isso a proposição de South (1977), para quem o refugo secundário divide-se em periférico (afastado) e adjacente (próximo) à unidade de habitação.

No sítio Vila Santo Antônio do Prata foram verificadas áreas de deposição de refugo na totalidade dos locais escavados. Em todas as elas o refugo é do tipo secundário, tendo em vista a verificação de bolsões de depósito intencionais associadas às estruturas arquitetônicas e com utilização até o momento em que a escavação foi realizada. A exceção corresponde apenas aos níveis mais profundos do Pavilhão D, mas o padrão não se observa nos estratos superiores. Apenas o Forno Crematório pode ser considerado área de deposição de refugo secundário Indexadores: Latindex, ISIS, Google Academic 
periférico, considerando a funcionalidade dessa estrutura arquitetônica e o período de sua construção. Apesar disso, os moradores atuais do entorno do Forno passaram a alocar e cremar lixo doméstico dentro e em volta da estrutura, configurando-o como refugo secundário adjacente. A Cozinha Geral e o Pavilhão $\mathrm{D}$, por outro lado, possuem depósitos com refugo secundário adjacente, tendo em vista tanto a deposição de entulho construtivo nas proximidades das edificações, quanto a presença de lixo doméstico e restos alimentares referentes a diferentes períodos.

As áreas escavadas, portanto, indicam dois diferentes padrões de práticas de descarte de refugo, alguns deles sobrepostos ao longo da ocupação da Vila, como é o caso do Forno Crematório e seu entorno. Esses padrões parecem estar associados, por um lado, com a pretensão de higiene, ordem e controle social que subjaz aos imperativos das instituições totais existentes na Vila Santo Antônio do Prata; e, por outro lado, ao cotidiano de internos, sejam eles doentes de hanseníase ou mesmo seus antecessores, os moradores da Colônia Indígena dirigida pelos padres Capuchinhos, entre 1898 e 1920, ou ainda os presos do Centro Correcional de 1921. Tais modificações nas regularidades de deposição indicam, portanto, comportamentos divergentes (SOUTH, 2007). Nesse último padrão, observa-se a recorrência de uma prática de descarte comum aos períodos anteriores à consolidação, no Brasil, da medicina moderna e do tipo de controle sobre os corpos que lhe é particular (LIMA, 1996; TOCCHETTO, 2010). Elas dizem respeito, portanto, às atividades cotidianas, nas quais é possível vislumbrar-se 
aspectos de transgressão às normas, reapropriação de valores e discursos, ou resistência a estes (TOCCHETTO, 2010).

A organização espacial do Núcleo Colonial Indígena, seguida pela reutilização dessa estrutura pelo Centro Correcional e, depois, Leprosário, implicavam na ordenação de arruamentos e edificações, de modo a garantir a pretensão de domínio e regulação, típicos de instituições totais e de controle (GOFFMAN, 1974; FOUCAULT, 1977, 1978; FRENCH, 1995; FLEXNER, 2012). A área central da Vila era pensada como "núcleo urbano" e, depois, "perímetro de isolamento". Era essa a área mais descrita nas fontes documentais, inclusive através de imagens que compunham os relatórios ou memoriais produzidos pelos agentes do Estado, responsáveis pela divulgação das instituições existentes no Prata.

Neste último caso, a divulgação de fotografias tinha a função de demonstrar a eficiência da instituição médica, inclusive no que tange aos aspectos de higiene e salubridade dos espaços de internamento. Nessas imagens é recorrente a visualização de ruas limpas, prédios conservados e arejados, construções novas destinadas à melhoria dos serviços, internos em atividades laborais e de lazer, zonas específicas para moradia e trabalho. $\mathrm{O}$ que se pretendia era enfatizar a necessária relação entre higiene e ordem, imprescindíveis no combate à lepra (SCHNEIDER, 2011). A construção do Forno Crematório está inserida neste contexto, tendo em vista sua finalidade para incineração de lixo. 
Apesar de não ter ocorrido escavação na porção interna (fornalha) do Forno Crematório, as tradagens do seu entorno imediato evidenciaram material remanescente de práticas hospitalares. Eles, portanto, dizem respeito à área de deposição de refugo secundário periférico, condizente com as pretensões de higiene e salubridade de uma instituição inserida no contexto da política sanitária responsável pela criação e manutenção dos leprosários no Brasil. A utilização constante do Forno até o período contemporâneo, com deposição e cremação de lixo doméstico e hospitalar, prolongou o contexto sistêmico de sua estrutura física para além dos tempos de funcionamento do estabelecimento médico. Além de permitir a manutenção de um tipo de prática de descarte de refugo, o constante uso também agiu na formação do registro arqueológico, dispersando material cremado na área de declive do Forno, o que foi exponenciado pela ação das águas pluviais.

As unidades de escavação no Forno, porém, demonstraram outro padrão de deposição de refugo que foi recorrente em outras áreas do sítio, tais como a formação de bolsões de lixo, de diferentes tamanhos e adjacentes às unidades de habitação (casas e pavilhões) ou de produção (Cozinha Geral). No caso do Forno Crematório, o material referente ao refugo secundário adjacente diz respeito às deposições recentes efetuadas pelos atuais moradores; verificados a partir da superfície, sua profundidade alcança no máximo os $10 \mathrm{~cm}$, acima do piso de cimento observado em quatro unidades de escavação. 
Esse padrão da população contemporânea parece ter profundidade temporal, considerando os bolsões verificados na Cozinha Geral e no Pavilhão D. Neste último, o refugo secundário adjacente é formado, em grande medida, pelos restos de material de construção provenientes das reformas e demolições da edificação: um bolsão que alcançou $47 \mathrm{~cm}$ de profundidade contendo entulho construtivo, com a porção superior selada por um horizonte de solo amarelado e endurecido. Nos níveis abaixo disso, poucos vestígios foram encontrados, estando limitados por um piso em concreto que não foi escavado. Como a porção posterior do Pavilhão é, atualmente, um terreno baldio, na superfície ocorre grande quantidade de lixo doméstico proveniente das casas do entorno. $\mathrm{O}$ padrão, portanto, é o similar ao verificado nos níveis arqueológicos superiores do entorno do Forno Crematório.

Em ambos os casos, ocorre refugo secundário adjacente, na porção posterior das edificações. Na Cozinha Geral, aparentemente, ocorrem diferentes bolsões de deposição de lixo. Apesar de apenas um deles ter sido escavado, foi possível verificar profundidades entre 40 e $60 \mathrm{~cm}$ com material arqueológico nas quatro unidades escavadas, com fragmentos posicionados verticalmente. Em algumas delas ocorria a associação com uma estrutura danificada de esgoto sanitário, com caixas sépticas e manilhas cerâmicas que partiam da Cozinha em direção ao rio Prata. O bolsão, na superfície, não apresentava material; no entanto, nas primeiras camadas da escavação observou-se a distribuição de entulho construtivo, selando 
o depósito de lixo. A diversidade do material indicou também práticas alimentares, aparentemente relativas ao Leprosário.

Por outro lado, a ocorrência de grande quantidade de garrafas de vidro chamou atenção, pela possibilidade de terem servido para armazenamento de bebidas alcoólicas. Algumas das garrafas estão inteiras, ou com partes significativas, e os fragmentos com gargalo ou base não apresentam indícios de modificações, tais como lascamento ou retoques. Evidentemente, frascos vítreos podem sofrer diferentes usos no contexto sistêmico, notadamente as garrafas de bebida (BUSCH, 1987; SCHIFFER, 1987; SYMANSKI 1996, SYMANSKI e OSÓRIO, 1996). Chama atenção, contudo, a associação dessas garrafas com embalagens de produtos industrializados, tais como leite, macarrão e café. Ao lado disso, não parece ser ocasional a deposição desses recipientes em uma área marginal ao centro urbano ou de isolamento, e próxima ao rio Prata, por onde há indicações orais de circulação de bebidas alcoólicas trazidas clandestinamente para o leprosário (LOPES, 2017).

A prática de descarte de lixo, orgânico ou não, na porção posterior da Cozinha e de outros prédios evidencia uma perspectiva de higiene contraditória ao que era argumentado pela da medicina de fins do século XIX e durante o funcionamento do leprosário, no século XX. Neste último período, a perspectiva de higiene esteve consubstanciada na organização espacial do leprosário e na construção de um prédio específico para tratamento do lixo hospitalar. Por outro lado, na porção posterior da Cozinha Geral, observa-se que o lixo "doméstico" era tratado sob 
outra perspectiva: eram depositados em buracos ou na encosta do rio Prata. Notase, contudo, que esses depósitos estavam fora das zonas de circulação constante.

Logo, os padrões de deposição de refugo verificados no sítio Vila Santo Antônio do Prata podem ser sintetizados da seguinte maneira, considerando a relação entre estruturas arquitetônicas e bolsões de lixo (Quadro 1):

\begin{tabular}{|c|c|c|c|}
\hline Tipo de refugo & Área/Estrutura & Período & $\begin{array}{c}\text { Característica do material } \\
\text { arqueológico }\end{array}$ \\
\hline $\begin{array}{c}\text { Secundário } \\
\text { periférico }\end{array}$ & Forno Crematório & \multirow{1}{*}{$\begin{array}{c}1940- \\
\text { atual }\end{array}$} & $\begin{array}{c}\text { - Ampolas de medicamentos; } \\
\text { - Instrumentais médicos }\end{array}$ \\
\cline { 2 - 4 } & $\begin{array}{c}\text { Entorno do Forno } \\
\text { Crematório }\end{array}$ & $\begin{array}{c}\text { - Lixo doméstico } \\
\text { contemporâneo }\end{array}$ \\
\cline { 2 - 4 } $\begin{array}{c}\text { Secundário } \\
\text { adjacente }\end{array}$ & Posterior ao Pavilhão D & $\begin{array}{c}1900- \\
\text { atual }\end{array}$ & $\begin{array}{c}\text { - Entulho construtivo } \\
\text { - Lixo doméstico } \\
\text { contemporâneo }\end{array}$ \\
\cline { 2 - 4 } & Posterior da Cozinha & $\begin{array}{c}1940- \\
\text { atual }\end{array}$ & $\begin{array}{c}\text { - Resíduos de lixo } \\
\text { provenientes da Cozinha } \\
\text { - Entulho construtivo }\end{array}$ \\
\hline
\end{tabular}

Quadro 1: Padrões de deposição de refugo, Sítio Vila Santo Antônio do Prata.

A existência desses dois padrões indica a imposição de um tipo de perspectiva de higiene, associada à política de controle sobre os doentes internos do leprosário do Prata. A ideia de isolamento do lixo produzido em diferentes contextos passou a ser frequente nos discursos e práticas de modernização da nação brasileira presentes desde meados do século XIX (LIMA, 1996; TOCCHETTO, 2010). A instalação dos leprosários no Brasil, desde a década de 1920, está associada ao 
discurso de modernidade necessário à evolução da República, em um contexto de ampliação da ação reguladora do Estado no âmbito da saúde (HOCHMAN, 1993; CABRAL, 2013). Dentro dos leprosários, cuidados com a higiene eram descritos como essenciais ao controle da doença. Fornos incineradores, sistemas de drenagem de esgoto e abastecimento de água faziam parte da estrutura dessas instituições (SOUZA ARAUJO, 1924, 1948). O cuidado com o lixo integrava o contexto geral brasileiro, principalmente a partir da década de 1930 (VARELA et al., 2015).

Contudo, os discursos de modernidade, associados ao higienismo, foram incorporados de maneira seletiva no Brasil, como demonstrou Tocchetto (2010) a partir de escavações em lixeiras domésticas de Porto Alegre. Para os contextos arqueológicos do século XIX, esta arqueóloga verificou a distribuição de bolsões de refugo distribuídos no entorno das casas; a exceção ocorreu em uma residência de família elitizada, com a presença também de buracos especificamente destinados ao lixo. Na Amazônia e no mesmo período, um contexto similar foi verificado por Symanski e Gomes (2012): descarte de lixo aleatório nos quintais de unidades domésticas da periferia da cidade de Santarém contrastavam com os buracos intencionalmente abertos com fins de deposição de lixo nas residências do bairro nobre. Em ambos os casos, a deposição aleatória está associada com perspectivas de higiene diferentes dos padrões médico-sanitários vigentes. 
No caso do sítio Vila Santo Antônio do Prata, observou-se depósitos de refugo referentes ao século XX, em outro contexto sanitário. A alocação de um lugar específico para processamento de resíduos está inserida nas normas de salubridade que argumentavam pelo afastamento do lixo das unidades domésticas, destinandoos às lixeiras coletivas (VARELA et al., 2015). Portanto, a existência de bolsões de depósito de lixo contíguos a uma unidade de produção de alimento, a Cozinha Geral, indica uma prática aparentemente contraditória no trato com o refugo. Isso não compreende um descarte aleatório, mas o despejo de lixo - principalmente orgânico - às proximidades da cozinha que produzia comida para os pacientes não parece estar em acordo com a noção de sanitarismo idealizada para um ambiente de atenção à saúde.

Assim, é possível que a formação da lixeira da Cozinha Geral tenha ocorrido no contexto de afrouxamento do controle sobre as práticas de higiene que não diziam respeito diretamente aos internos do leprosário. Para outras áreas não-escavadas no sítio Vila Santo Antônio do Prata, há informações orais sobre a existência de lixeiras nos fundos dos quintais das casas construídas para as famílias de doentes de hanseníase internados a partir de 1924. A prática começou a diminuir com os serviços públicos de coleta de resíduos, no início do século XXI. De todo modo, ao que parece, a tendência era pensar que o lixo que entrou em contato com os doentes era mais perigoso do que qualquer outro. 
Além disso, a relação de oposição entre dentro/frente/limpo versus fora/fundo/sujo parece estar presente na constituição do cotidiano nos diferentes períodos históricos da Vila Santo Antônio do Prata. Tocchetto (2010) estabeleceu essas oposições para ambientes domésticos, nos quais os espaços de deposição de lixo nos fundos ou laterais das residências foram interpretados como os lugares da ocultação da sujeira. Por outro lado, os ambientes internos e as fachadas das casas são lidos como lugares da limpeza, nos quais ocorrem as interações sociais pautadas nos discursos de salubridade. Apesar do modelo proposto por Tocchetto (2010) dizer respeito a ambientes residenciais no sul do Brasil, e não às instituições de controle, ele informa sobre a consolidação dos paradigmas higienistas no cotidiano brasileiro e suas reapropriações particulares neste país. As diferentes instituições de controle existentes na Vila do Prata incorporavam nos seus pressupostos estas noções de salubridade, o que torna válido tais considerações para refletir os contextos arqueológicos aqui analisados. A recorrência de dessas práticas na Amazônia, apontadas por Symanski e Gomes (2012) para o mesmo período porto alegrense, sustentam tal argumento.

Paralelamente, pesquisas em outros locais têm demonstrado que a normatização de comportamentos, observada nos registros históricos, possuía limitações ou possibilidades de transgressões. Flexner (2011, 2012), ao investigar o leprosário de Kalawao, no Havaí, demonstrou que práticas cotidianas dos internos destoavam das características de uma instituição total, seja no que tange à organização do lugar, seja nas práticas alimentares. Neste caso, a partir dos dados 
arqueológicos, foi possível verificar que as relações sociais estavam condicionadas pelos códigos culturais locais, baseados na tradição. Sua investigação sugere que as dinâmicas de poder produzidas em um leprosário moderno eram mais complexas do que costuma ser observado nos documentos produzidos pelos seus administradores.

Por um lado, a possibilidade de agência dos internos era reprimida com a estrutura organizacional, tendo em vista o controle ou manutenção de diferenças sociais, como demonstrou French (1995), para o caso do leprosário canadense D’Arcy Island. Em oposição a isso, atos de resistência ocorreram fora da vigilância dos funcionários e administradores (FLEXNER, 2012). Na Vila Santo Antônio do Prata, sugere-se a partir do registro arqueológico, que as normas rígidas de higiene conviviam com hábitos cotidianos de descarte de lixo, praticados pelos próprios empregados das instituições que, no caso do leprosário, podiam ser também os internos. O refugo oriundo da produção de alimentos da Cozinha Geral era descartado às margens do local. Outro tipo de atenção é observado ao material que dizia respeito aos cuidados imediatos com a hanseníase ou diretamente manipulado pelos doentes, incinerados no Forno Crematório.

\section{CONCLUSÃO}

A trajetória histórica do Prata, ensejada na atuação do Estado para com os grupos que lá habitaram, implica em pensar o contexto arqueológico, também 
característicos de seu processo de ocupação. Desse modo, duas dimensões de análise são viáveis, indo além da perspectiva de investigação da paisagem construída. A primeira, diz respeito à condução das ações de governo direcionadas ao lugar, via instituições de controle dos corpos. O projeto para disciplinar os sujeitos mantidos nos limites do Prata, possuía pretensões totalizantes, com práticas que submetiam as pessoas ao controle de um superior, disseminado nas relações de poder dos moradores (BELTRÃO e LOPES, 2014; FERNANDES, 2015). Nesse sentido, argumentei que a infraestrutura material desta instituição foi constituída enquanto tecnologia de poder sobre os corpos dos grupos a ela submetidos, com objetivos de políticas de Estado que tinham como pressuposto o binômio exclusão e reclusão (LOPES, 2017).

Por outro lado, a segunda dimensão de análise diz respeito às relações de poder cotidianas, pouco ou nada registradas nos documentos oficiais dos administradores das instituições disciplinares do Prata. A arquitetura do lugar sofreu adaptações de acordo com os modos de domínio dos corpos do público alvo desses controladores. Todavia, informações orais indicam que os internos possuíam diferentes meios de burlar a supervisão constante e os limites conformados nas edificações (LOPES, 2017).

A condução das escavações arqueológicas no sítio Vila Santo Antônio do Prata resultou no acréscimo de outro nível de informação a esse cotidiano. O descarte de refugo não parece ter sido efetuado de maneira unívoca, sempre de acordo com 
as normas de controle e higiene das instituições. Ao contrário, as diferentes práticas diferiam entre si e parecem ter convivido ao longo da trajetória do lugar.

\section{REFERÊNCIAS BIBLIOGRÁFICAS}

BELTRÃO, J. F.; LOPES, R. C. S. 2014. Diásporas, homogeneidades e pertenças entre os Tembé Tenetehara de Santa Maria. ACENO, 1(1):123-143.

BUSCH, J. 1987. Second Time Around: A Look at Bottle Reuse. Historical Archaeology, 21:68-80.

CABRAL, D. 2013. Lepra, medicina e políticas de saúde no Brasil (18941934). Coleção História e Saúde. Rio de Janeiro: Editora Fiocruz.

CASELLA, E. C. 2016. Horizons beyond the Perimeter Wall: Relational Materiality, Institutional Confinement, and the Archaeology of Being Global. Historical Archaeology, 50 (3):127-143.

CRUZ, E. 1955. A Estrada de Ferro de Bragança: visão social, econômica e política. Belém: SPVEA.

FERNANDES, R. F. 2015. Tembé Tenetehara de Santa Maria do Pará: Retomando os fios da história. Estudos Amazônicos, XIII (1):214-249.

FLEXNER, J. L. 2012. An Institution that was a Village: Archaeology and Social Life in the Hansen's Disease Settlement at Kalawao, Moloka ‘i, Hawaii. Int. J. Histor. Archaeol., $16: 135-163$.

FLEXNER, J. L. 2011. Foreign Animals, Hawaiian Practices: Zooarchaeology in the Leprosarium at Kalawao, Moloka ‘i, Hawaii. Journal of Pacific Archaeology, 2 (1):82-91.

FOUCAULT, M. 1979. Microfísica do poder. Rio de Janeiro: Edições Graal.

FOUCAULT, M. 1978. História da Loucura. São Paulo: Perspectiva

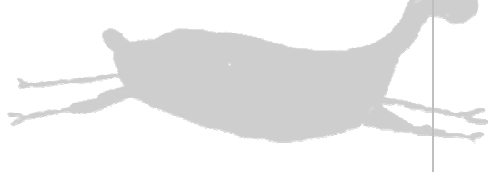


FOUCAULT, M. 1977. Vigiar e Punir. Petrópolis: Vozes.

FRENCH, D. E. 1995. Ideology, politics and power: the socio-historical of the Archaeology of the D'Arcy Island Leper Colony, 1891-1924. Tese de doutorado. Vancouver, The University of British Columbia.

GOFFMAN, E. 1974. Manicômios, prisões e conventos. São Paulo: Editora Perspectiva.

HOCHMAN, G. 1993. Regulando os Efeitos da Interdependência: sobre as relações entre saúde pública e construção do Estado (Brasil 1910-1930). Estudos históricos, 6 (11):4061.

LIMA, T. A. 1996. Humores e odores: ordem corporal e ordem social no Rio de Janeiro, século XIX. História, Ciências, Saúde. Manguinhos, 2 (3):46-98.

LOPES, R. C. S. 2017. Tempos, espaços e cultura material na Vila Santo Antônio do Prata, Pará - Arqueologia em uma instituição total amazônica. Tese de Doutorado. Belém, Universidade Federal do Pará.

LOPES, R. C. S.; SCHAAN, D. P. 2016. Projeto arqueológico Vila Santo Antônio do Prata, Igarapé-Açu (PA). Relatório final. Belém, Universidade Federal do Pará.

MUNIZ, P. 1913. O Instituto do Prata (Município de Igarapé-Assú). Belém: Typ. da Livraria Escolar.

NORTE, F. 1930. Nos arraiais do Prata, Lazaropolis, a ridente cidade da consolação II. Folha do Norte, 12.606:1.

REDMAN, C. L. 1973. Multistage fieldwork and analytical techniques. American Antiquity, (38):61-79.

SCHIFFER, M. B. 1987. Formation processes of the archaeological record, 1st edition. Albuquerque, NM: University of New Mexico Press.

SCHIFFER, M. B. 1985. Is There a "Pompeii Premise" in Archaeology? Journal of Anthropological Research, 41 (1):18-41. 
SCHNEIDER, S. D. 2011. Lepra: fotografia e discurso na obra de Souza-Araújo (19161959). Dissertação de Mestrado. Marechal Cândido Rondon, Universidade Estadual do Oeste do Paraná.

SOUTH, S. 2007. Reconhecimento de padrões na arqueologia histórica. Vestígios Revista Latino-Americana de Arqueologia Histórica, 1 (1):135-149.

SOUTH, S. 1977. Method and Theory in Historical Archaeology. New York: Academic Press.

SOUZA ARAUJO, H. C. 1948. História da lepra no Brasil - Período republicano (18891946). Vol. II. Rio de Janeiro: Imprensa Nacional.

SOUZA ARAUJO, H. C. 1924. Lazaropolis do Prata: a primeira colonia agrícola de leprosos fundada no Brasil. Belém: Empreza Graphica Amazonia.

SOUZA, R. A. 2014. Arqueologia na metrópole paulistana. Habitus, 12 (1):23-44.

SUGUIMATSU, I. C.; SYMANSKI, L. C. P. 2015. Atividades cotidianas, deposição de refugo e ação do arado: processos de formação do registro arqueológico no espaço de uma senzala de Campos dos Goytacazes (RJ). Clio Arqueológica, 30 (1):38-76.

SYMANSKI, L. C. P. 1996. Bebidas, panacéias, garrafas e copos: a amostra de vidros do Solar Lopo Gonçalves. Revista de Arqueologia, 11:71-86.

SYMANSKI, L. C. P.; GOMES, D. M. C. 2012. Mundos mesclados, espaços segregados: cultura material, mestiçagem e segmentação no sítio Aldeia em Santarém (PA). Anais do Museu Paulista, 20(2):53-90.

SYMANSKI, L. C. P.; GOMES, F. D. S.; SUGUIMATSU, I. C. 2015. Práticas de descarte de refugo em uma plantation escravista: o caso da fazenda do colégio dos jesuítas de Campos dos Goytacazes. Revista de Arqueologia, 28 (1):93-122.

SYMANSKI, L. C. P.; OSÓRIO, S. R. 1996. Artefatos recliclados em sítios arqueológicos de Porto Alegre. Revista de Arqueologia, 9:43-54.

Indexadores: Latindex, ISIS, Google Academic 
TOCCHETTO, F. B. 2010. Fica dentro ou joga fora? Sobre práticas cotidianas na Porto Alegre moderna oitocentista. São Leopoldo: Oikos.

VALDEVINO, G. D. C. M.; AMARAL, R. D. S. 2017. Projeto arqueológico Vila Santo Antônio do Prata, Igarapé-Açu (PA). Relatório de anásile osteológica. Manaus, Instituto Nacional de Pesquisa da Amazônia/Instituto Federal de Educação, Ciência e Tecnologia do Amazonas.

VARELA, A. M.; OLIVEIRA, E. A. D.; SUGUIMATSU, I. C.; ROSA, L. A. S. D.; RODET, M. J.; SUENNY, T.; LEITE, W. A. 2015. Corpo são, cidade limpa: uma arqueologia do sanitarismo e higienização em Belo Horizonte, 1930-1960. Teoria; Sociedade, 23 (1):198-236.

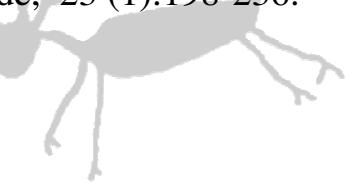

